\title{
Responses and post-impact properties of ultra-high performance fibre reinforced concrete under pendulum impact
}

\section{Citation for published version (APA):}

$\mathrm{Li}, \mathrm{P}$. ., \& Yu, Q. (2019). Responses and post-impact properties of ultra-high performance fibre reinforced concrete under pendulum impact. Composite Structures, 208, 806-815.

https://doi.org/10.1016/j.compstruct.2018.10.071

\section{Document license:}

TAVERNE

DOI:

10.1016/j.compstruct.2018.10.071

Document status and date:

Published: 15/01/2019

\section{Document Version:}

Publisher's PDF, also known as Version of Record (includes final page, issue and volume numbers)

\section{Please check the document version of this publication:}

- A submitted manuscript is the version of the article upon submission and before peer-review. There can be important differences between the submitted version and the official published version of record. People interested in the research are advised to contact the author for the final version of the publication, or visit the $\mathrm{DOI}$ to the publisher's website.

- The final author version and the galley proof are versions of the publication after peer review.

- The final published version features the final layout of the paper including the volume, issue and page numbers.

Link to publication

\section{General rights}

Copyright and moral rights for the publications made accessible in the public portal are retained by the authors and/or other copyright owners and it is a condition of accessing publications that users recognise and abide by the legal requirements associated with these rights.

- Users may download and print one copy of any publication from the public portal for the purpose of private study or research.

- You may not further distribute the material or use it for any profit-making activity or commercial gain

- You may freely distribute the URL identifying the publication in the public portal.

If the publication is distributed under the terms of Article 25fa of the Dutch Copyright Act, indicated by the "Taverne" license above, please follow below link for the End User Agreement:

www.tue.nl/taverne

Take down policy

If you believe that this document breaches copyright please contact us at:

openaccess@tue.nl

providing details and we will investigate your claim. 


\title{
Responses and post-impact properties of ultra-high performance fibre reinforced concrete under pendulum impact
}

\author{
P.P. Li, Q.L. Yu* \\ Department of the Built Environment, Eindhoven University of Technology, P.O. Box 513, 5600 MB Eindhoven, The Netherlands
}

\section{A R T I C L E I N F O}

\section{Keywords:}

UHPFRC

Impact responses

Post-impact properties

Repeated pendulum impact

Damage index

Analytical modelling

\begin{abstract}
A B S T R A C T
The present research aims to understand the response and post-impact properties of ultra-high performance fibre reinforced concrete (UHPFRC) under low-velocity impact. An UHPFRC applying coarse basalt aggregate is developed by using the optimized particle packing theory and considering the mineral oxide engineering and steel fibre utilization. A reliable low-velocity impact method employing pendulum impact test set-up is designed and applied. The results show that the residual strength of UHPFRC beams after impact follows ' $-e^{x}$, law with the number of impact, while the residual rigidity, toughness and impact resistance tend to linearly decrease. The rigidity and toughness are more appropriate indicators than ultimate bearing capacity based on the analysis on damage index. An analytical model is proposed to predict the residual impact resistance of UHPFRC beams with the static property of flexural toughness and validated against the experimental data.
\end{abstract}

\section{Introduction}

Ultra-high Performance Fibre Reinforced Concrete (UHPFRC) is a relatively new building composite material, which has superior mechanical strength, impact resistance, fatigue resistance and durability [1-6]. Those excellent characters and properties make it suitable to be used in impact resistant components and structures, such as protective elements in military and municipal engineering.

The excellent impact resistance of UHPFRC is greatly dependent on raw materials and mix design methods, such as water-to-binder ratio, mineral admixture condition, powder content, and aggregate size and content. Currently, most UHPFRCs are designed by using only fine aggregates or refined aggregates $[2,3,7,8]$, in order to avoid the limit of intrinsic strength of coarse aggregate, overcome the inherent weakness of interfacial transition zone, increase the homogeneity and eliminate stress concentration at the contact points between aggregates. However, concrete containing appropriate type and content of coarse aggregate can possess certain advantages, such as reduced autogenous shrinkage [3], improved elastic modulus and workability [9], enhanced stress-strain behaviour of confined concrete [10]. A slightly higher strength of concrete in presence of coarse aggregate has also been observed $[11,12]$. Our previous research further proved that the incorporation of coarse basalt aggregate to UHPFRC induces rather limited decrease on the mechanical strength, while greatly reduces the powder amount, consequently cost of UHPFRC [13]. Nevertheless, investigation on the effect of coarse aggregate on properties of UHPFRC under impact loading is still very limited. In addition, basalt aggregate exhibits a better intrinsic strength than ordinary rock [14], which is potentially more suitable to match the high strength of paste matrix of UHPFRC. Hence, the properties of UHPFRC with coarse basalt aggregate under impact loading need to be investigated.

In recent years, numerous experimental and analytical studies have focused on responses and properties of UHPFRC under high-velocity impact loading, such as bullet or projectile impact test, blast test and split-Hopkinson bar test [15-17]. Nevertheless, the impact responses and post-impact properties of UHPFRC under low-velocity impact loading are also of great significance and can provide insights on specific practical problems, such as vehicle impact on concrete infrastructure during traffic accident, ship collision on bridges' pillars or offshore structures, falling object impact on concrete slab, wheel-rail interaction on concrete sleeper [18,19], etc. However, it is noticed that no standard low-velocity impact testing methods for UHPFRC are available currently. Drop-weight test and modified Charpy system recommended by ACI Committee 544 are widely used [20-24]. However, these low-velocity impact testing methods are not appropriate for evaluating UHPFRC because of certain drawbacks. A high standard deviation and coefficient of variation from ACI repeated drop-weight impact test are usually observed, even more than $50 \%$ of coefficients of variation [21]. The number of impact is too large for fibre reinforced concrete, sometimes as high as 1000 blows [22]. The Charpy type

\footnotetext{
* Corresponding author.

E-mail address: q.yu@bwk.tue.nl (Q.L. Yu).
} 
impact test can only measure small geometrical size of specimen with short fibres [24]. The drop-weight impact test usually has a rebounded and secondary impact effect, when the specimens do not completely damage [25]. Hence, it is necessary to develop a new low-velocity impact experimental method for UHPFRC.

Besides, the majority of current studies only place emphasis on investigating the total impact number and energy absorption under repeated low-velocity impact loading. Researches concerning impact responses and post-impact properties assessment are rather scarce. Both crack propagation and damage pattern are critical factors to interpret impact response and resistant mechanism of UHPFRC. Furthermore, residual property (e.g. compressive strength after impact) is one of the most crucial parameters for damaged composite materials [26], which is widely used to evaluate the damage degree and health status of structures and components under extreme conditions, such as residual strength after fatigue loading, freeze-thaw cycles or high temperature exposure [27-29]. The investigation on post-impact properties (e.g. residual strength, stiffness, toughness, impact resistance) can provide key parameters and bases for the design of protective elements and components. Nevertheless, impact resistance (energy absorption capacity) of UHPFRC is much more difficult to be determined than other static properties, due to the complexity of impact test. For these reasons, necessity to investigate the impact responses and post-impact properties of UHPFRC under repeated low-velocity impact loading, and to propose a reliable analytical model to predict the impact resistance by several key variables based on simple static tests is evident.

The objective of this paper is to design a reliable repeated low-velocity impact testing device and method, investigate the impact responses and post-impact properties of UHPFRC with coarse basalt aggregate, and classify the damage levels by analysing the damage index. Furthermore, an analytical model is proposed to predict the residual impact resistance of UHPFRC beams with the static property of flexural toughness and validated against the experimental data.

\section{Experimental program}

\subsection{Materials}

The raw materials used in this study are Portland cement CEM I 52.5 $\mathrm{R}$ (PC), micro-silica (mS), limestone powder (LP), silica sand (S), coarse basalt aggregate (BA), tap water (W), PCE-type superplasticizer (SP) and steel fibre (SF). The specific densities of those ingredients were measured by a gas pycnometer (AccuPyc 1340 II Pycnometer ${ }^{\circledast}$ ), shown in Table 1. The particle size distributions (PSD) of the used materials were measured by the sieve and laser diffraction analyses (Malvern Mastersizer $2000^{\circledR}$ ), respectively, shown in Fig. 1. The chemical compositions of the used powders were tested by X-ray Fluorescence (XRF), shown in Table 2. Table 3 exhibits the characteristics of utilized steel fibre.

\subsection{Mix design}

The recipe of UHPFRC in this study is illustrated in Table 4. A PCEtype superplasticizer is utilized to achieve a desired fluidity with a dosage of $1.6 \%$ by the weight of total powder, based on the previous study [30]. The optimal proportion of powders is $5 \%$ of micro-silica and $20 \%$ of limestone powder by mass of the total powder, by considering the flow ability, mechanical strength and drying shrinkage of UHPFRC

Table 1

Specific densities of raw materials.

\begin{tabular}{lllllllll}
\hline Materials & CEM & $\mathrm{mS}$ & LP & $\mathrm{S}$ & BA 2-5 & BA 2-5 & W & SP \\
\hline $\begin{array}{c}\text { Specific density (g/ } \\
\mathrm{cm}^{3} \text { ) }\end{array}$ & 3.15 & 2.32 & 2.71 & 2.72 & 3.05 & 2.89 & 1.00 & 1.07 \\
\hline
\end{tabular}

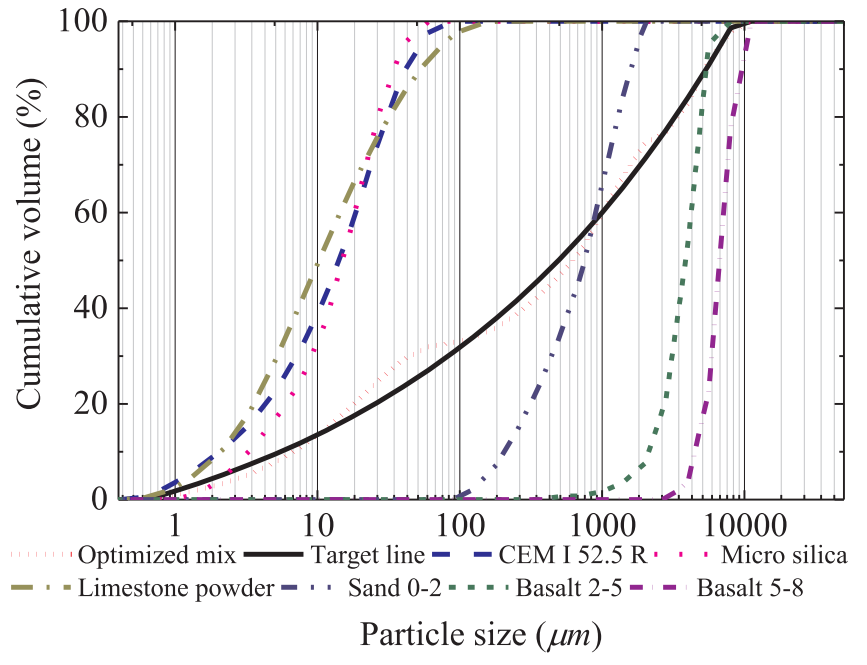

Fig. 1. The PSD of raw materials and designed UHPFRC matrix.

pastes [13]. The dosage of steel fibre is $2 \%$ vol. of the UHPFRC, which is proven to be an appropriate dosage for UHPFRC $[4,31]$. The fractions of aggregates are determined by applying the Brouwers method [32-36],

$P(D)=\frac{D^{q}-D_{\min }^{q}}{D_{\max }^{q}-D_{\min }^{q}}$

where $D$ is the particle size $(\mu \mathrm{m}), D_{\min }$ and $D_{\max }$ represent the minimum and maximum particle size, respectively $(\mu \mathrm{m}) . P(D)$ is the cumulative fraction of the total solids being smaller than size $D . q$ is the distribution modulus, which is greatly dependent on the type of concrete $[37,38]$. A relatively low $q$ value of 0.19 in our previous study is proposed and suggested for UHPFRC containing coarse aggregate and relatively low powder content [13]. The PSDs of the target and designed curve of UHPFRC matrix are shown in Fig. 1. The casting and curing of the concrete follow the same procedure as presented in the previous study [13].

\subsection{Testing methods}

\subsubsection{Fresh behaviour}

The spread flow of UHPFRC was measured by using a truncated conical mould (Abrams cone: height $300 \mathrm{~mm}$, top diameter $100 \mathrm{~mm}$, base diameter $200 \mathrm{~mm}$ ), in accordance with EN 12350-8: 2007 [39]. Fresh concrete was filled in the mould and the cone was lifted straight upwards to allow the concrete flow freely without jolting. The spread flow was calculated by the average value of two perpendicular diameters. The flow test was conducted at room temperature of about $20 \pm 1{ }^{\circ} \mathrm{C}$. The fresh concrete was filled in a cylindrical container of known volume, and then its mass was determined to calculate the fresh density.

\subsubsection{Compressive and tensile splitting strength}

The fresh UHPFRC was casted into steel moulds $\left(100 \times 100 \times 100 \mathrm{~mm}^{3}\right)$ for compressive and tensile splitting strength test. All samples were covered with polyethylene film to prevent the moisture loss. They were demoulded approximately $24 \mathrm{~h}$ after casting and then cured in water under room temperature of $20 \pm 1{ }^{\circ} \mathrm{C}$. The compressive and tensile splitting strength of UHPFRC samples were measured following the specifications set in the standards EN 12390-3: 2009 [40] and EN 12390-6: 2009 [41], respectively, at different curing ages.

\subsubsection{Pendulum impact test}

As discussed above, a novel and reliable testing set-up and method for repeated low-velocity impact needs to be designed to research the 
Table 2

Chemical composition of powders.

\begin{tabular}{|c|c|c|c|c|c|c|c|c|c|c|}
\hline Substance (\%) & $\mathrm{CaO}$ & $\mathrm{SiO}_{2}$ & $\mathrm{Al}_{2} \mathrm{O}_{3}$ & $\mathrm{Fe}_{2} \mathrm{O}_{3}$ & $\mathrm{~K}_{2} \mathrm{O}$ & $\mathrm{Na}_{2} \mathrm{O}$ & $\mathrm{SO}_{3}$ & $\mathrm{MgO}$ & $\mathrm{TiO}_{2}$ & $\mathrm{MnO}$ \\
\hline CEM & 67.02 & 16.80 & 4.14 & 3.48 & 0.23 & - & 4.14 & 1.67 & 0.27 & 0.09 \\
\hline $\mathrm{mS}$ & 0.90 & 93.06 & - & 2.06 & 1.15 & 0.63 & 1.28 & 0.70 & - & 0.07 \\
\hline LP & 97.21 & 0.87 & 0.17 & 0.13 & - & - & 0.11 & 1.17 & 0.01 & 0.01 \\
\hline
\end{tabular}

impact responses and post-impact properties of UHPFRC. Impact tests can be divided into three categories (qualitative, semi quantitative and quantitative), depending on the property measured by which the impact test is conducted. But quantitative interpretation of impact testing results to derive inherent physical material parameters has shown to be still quite difficult. Furthermore, impact tests should follow some primary criterion and achieve goals as: (1) simple to handle; (2) energy sufficient to fracture the specimen; and (3) number of blows to achieve a specified distress level [42].

In this study, the repeated low-velocity impact test was carried out by using a pendulum set-up (length $12 \mathrm{~m}$, width $4 \mathrm{~m}$, height $6 \mathrm{~m}$ ), shown in Fig. 2. The impact height can be adjusted from 0 up to $4 \mathrm{~m}$, while the impact mass can be changed from about $22 \mathrm{~kg}$ to $40 \mathrm{~kg}$. The point-contact hammer, released from a certain height, impacts the hanging concrete specimen perpendicularly at the lowest position. The velocities of hammer and specimen, before and after impact, are measured by the high-speed camera by recording movement during short period of time. The frame rate of high-speed camera is set at 5000 frames per second, and the displacement of movement is measured around $5 \mathrm{~cm}$ based on a white board background with centimetre grids drawn on it. The impact resistance of UHPFRC can be described by the energy absorbed by the specimen. The absorbed energy during a single impact can be calculated by using,

$E=1 / 2 M_{h} V_{0}^{2}-1 / 2 M_{h} V_{r}^{2}-1 / 2 M_{s} V_{s}^{2}$

where the $E$ is the absorbed energy by specimen during a single impact (J); $M_{h}$ and $M_{s}$ are the masses of hammer and specimen (kg), which are $30.3 \mathrm{~kg}$ and $31.7 \mathrm{~kg}$, respectively; $V_{0}$ and $V_{r}$ are the velocities of hammer before and after impact $(\mathrm{m} / \mathrm{s})$, the hammer is released from the height of $1.4 \mathrm{~m}$ and the initial impact velocity $V_{0}$ for each impact is approximately $4.78 \mathrm{~m} / \mathrm{s} ; V_{s}$ is the velocity of concrete beam after impact $(\mathrm{m} / \mathrm{s})$ and assumed as a constant, because inertia induced self-vibration is very limited compared to the kinetic velocity and very short (usually 1 or $2 \mathrm{~ms}$ ) compared to measuring period (tens of milliseconds in this study) $[43,44]$. The mass and initial velocity of hamper is chosen after preliminary trials in order to acquire a moderate impact number. The impact is repeated several times till a pre-designed impact number or complete failure of specimen.

Standard notched beam has been recommended by various organizations such as RILEM TC 162 [45] and EN 14651 [46] to test the impact resistance of concrete [47]. The notch is made on the rear surface of beam. It has been reported that the variations of conventional drop-weight impact results are often very high, attributed to the shape of specimen $[48,49]$. This is also observed in the preliminary experiments during this study. Notched specimens tend to reduce the variations of testing results, attributed to certain fracture path along the notch plane [50]. Furthermore, it is also convenient to evaluate the post-impact properties of this kind of specimen, which will be discussed in following sections.

To sum up, this proposed impact testing method has several advantages in comparison with conventional drop-weight test. Firstly, the
Table 4

Recipe of designed UHPFRC.

\begin{tabular}{|c|c|c|c|c|c|c|c|c|c|}
\hline Materials & $\begin{array}{l}\mathrm{PC} \\
(\mathrm{kg} / \\
\left.\mathrm{m}^{3}\right)\end{array}$ & $\begin{array}{l}\mathrm{mS} \\
(\mathrm{kg} / \\
\left.\mathrm{m}^{3}\right)\end{array}$ & $\begin{array}{l}\mathrm{LP} \\
(\mathrm{kg} / \\
\left.\mathrm{m}^{3}\right)\end{array}$ & $\begin{array}{l}\mathrm{S} 0-2 \\
(\mathrm{~kg} / \\
\left.\mathrm{m}^{3}\right)\end{array}$ & $\begin{array}{l}\mathrm{BA} \\
2-5 \\
(\mathrm{~kg} / \\
\left.\mathrm{m}^{3}\right)\end{array}$ & $\begin{array}{l}\text { BA } \\
5-8 \\
(\mathrm{~kg} / \\
\left.\mathrm{m}^{3}\right)\end{array}$ & $\begin{array}{l}\mathrm{W} \\
(\mathrm{kg} / \\
\left.\mathrm{m}^{3}\right)\end{array}$ & $\begin{array}{l}\mathrm{SP} \\
(\mathrm{kg} / \\
\left.\mathrm{m}^{3}\right)\end{array}$ & $\begin{array}{l}\text { SF } \\
\text { Vol. } \\
\%\end{array}$ \\
\hline Quantity & 588 & 39.2 & 156.8 & 839.9 & 413.2 & 232.3 & 187.8 & 12.6 & $2 \%$ \\
\hline
\end{tabular}

different swing movements between hammer and specimen can eliminate rebound and secondary impact during each full impact. Secondly, the acquired impact resistance (absorbed energy) should be more accurate based on kinetic energy difference, because the absorbed energy is normally calculated by impact number and gravitational potential energy $[23,24,28]$. However, the specimen cannot absorb all potential energy, which leads to an overestimated impact resistance. Thirdly, the variation of results should be lower based on notched specimens. Lastly, the pendulum set-up is easily compatible with most low-velocity impact tests of UHPFRC and a moderate impact number is sufficient, due to the flexible change of specimen (e.g. shape and size) and hammer (e.g. shape, mass and height).

\subsubsection{Central point bending test}

During the repeated pendulum impact test, impact responses of UHPFRC can be collected, such as crack propagation, damage pattern and energy dissipation. Meanwhile, partially and completely damaged beams will be collected. To analyse the post-impact properties and research correlations between impact resistance and basic key static parameters, the flexural behaviours of both original and partially damaged beams after a certain impact number are subsequently measured, based on RILEM TC 162-TDF [45]. Some UHPFRC beams and central point bending set-up are shown in Fig. 3. Based on the load-deflection curve, the corresponding post-impact properties can be deduced, such as residual strength, rigidity and toughness, as well as damage index and levels.

\section{Results and discussion}

\subsection{Fresh and static behaviours}

The fresh properties and static strengths of the designed UHPFRC are presented in Table 5. The slump flow and fresh density of the designed UHPFRC are approximately $560 \mathrm{~mm}$ (class of SF2 according to SCC guideline [51]) and $2562 \mathrm{~kg} / \mathrm{m}^{3}$, respectively. The excellent slump flow can be explained by the used PCE-type superplasticizer, high limestone powder content, utilization of coarse aggregate, as well as the achieved optimal packing of the solid ingredients. The PCE molecules are adsorbed onto particles and separated by opposing their attractive forces with steric and/or electrostatic forces, which then disperse the particles, release the free water and increase fluidity [30]. The

Table 3

Characteristics of steel fibre.

\begin{tabular}{|c|c|c|c|c|c|c|c|}
\hline Length (L) (mm) & Fibre shape & Bundling & Diameter (d) (mm) & Aspect ratio (L/d) & Density $\left(\mathrm{kg} / \mathrm{m}^{3}\right)$ & Tensile Strength (MPa) & Elastic Modulus (GPa) \\
\hline 13 & Straight & Loose & 0.2 & 65 & 7850 & 2750 & 200 \\
\hline
\end{tabular}



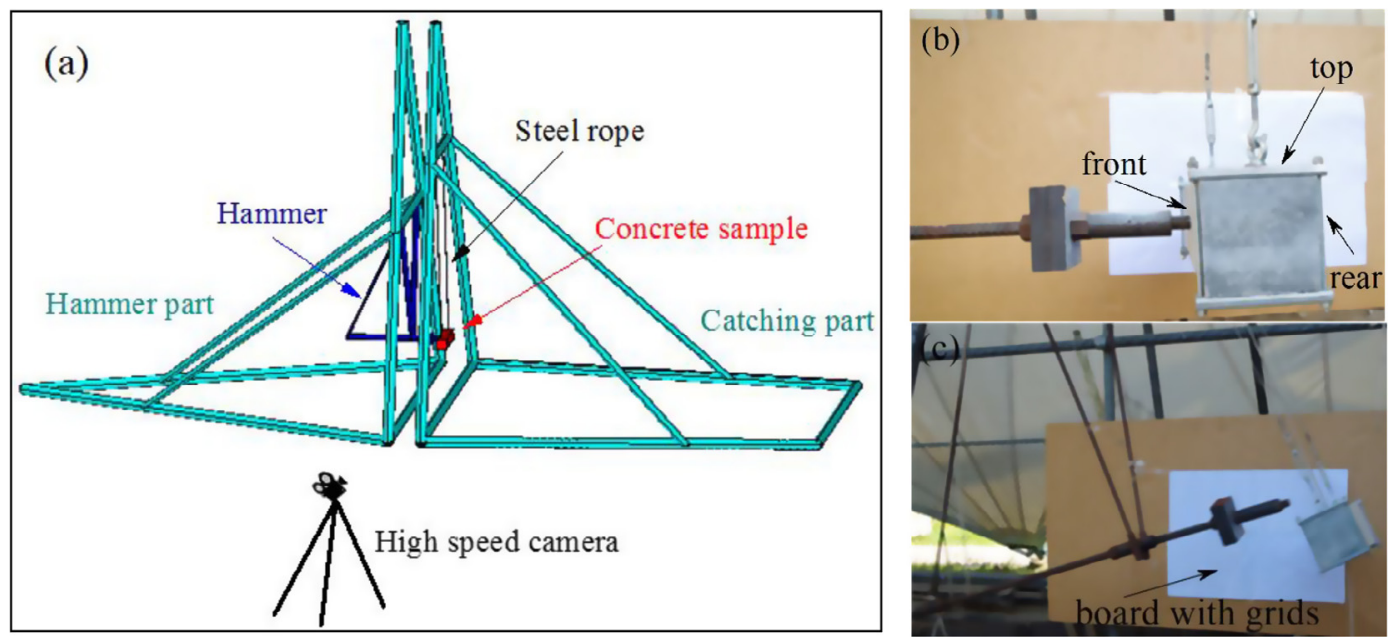

Fig. 2. Pendulum impact set-up: scheme (a), before (b) and after (c) impact.

limestone powder increases the workability because of its low water demand and electrostatic repulsion effect by localizing the $\mathrm{Ca}^{2+}$ surface with the groups of $\mathrm{OH}^{-}$[52]. Compared to finer aggregates, coarse aggregate has lower surface area, which contributes to improved workability [9]. The optimal packing ensures more water available to lubricate the system and provide better workability [53].

The compressive strengths are 141.1 MPa and 153.4 MPa after the curing age of $28 \mathrm{~d}$ and $91 \mathrm{~d}$, respectively. The tensile splitting strengths are $16.3 \mathrm{MPa}$ and $18.1 \mathrm{MPa}$ at $28 \mathrm{~d}$ and $91 \mathrm{~d}$, respectively, which is greatly attributed to the reinforcement of steel fibre by comparing the results with our previous research [13]. The development of compressive strength demonstrates that most hydration and strength development occur within the first 2 weeks and further increase relatively mildly. To further demonstrate the advantages of the designed UHPFRC, the concept of the binder efficiency is utilized,

$X_{\text {binder }}=\sigma_{c} / m_{\text {binder }}$

where $X_{\text {binder }}$ is the binder efficiency, $\sigma_{c}$ is the compressive strength of concrete (MPa) and $m_{\text {binder }}$ is the total mass of the binders $(\mathrm{kg})$ including Portland cement and micro-silica in this study, the limestone powder is regarded as filler. The binder efficiencies of the designed UHPFRC in this study can reach up to 0.225 and 0.245 after 28 and 91 days, respectively, which is much higher than the values of previously reported UHPFRCs under similar curing conditions and dosage of steel fibre $[4,7,38,54-58]$, as illustrated in Fig. 4. The high binder efficiency of the designed UHPFRC is attributed to the following reasons: (1) low powder content because of the applied coarse basalt aggregate; (2) dense and homogeneous skeleton with utilization of the modified packing model and optimum distribution modulus; (3) optimal mineral condition by considering positive synergic effect.
Table 5

Fresh properties and strengths of UHPFRC.

\begin{tabular}{llllll}
\hline $\begin{array}{l}\text { Spread flow } \\
(\mathrm{mm})\end{array}$ & $\begin{array}{l}\text { Fresh } \\
\text { density }(\mathrm{kg} / \\
\left.\mathrm{m}^{3}\right)\end{array}$ & $\begin{array}{l}28 \mathrm{~d} \\
\sigma_{c}(\mathrm{MPa})\end{array}$ & $\begin{array}{l}91 \mathrm{~d} \\
\sigma_{c}(\mathrm{MPa})\end{array}$ & $\begin{array}{l}28 \mathrm{~d} \\
\sigma_{t}(\mathrm{MPa})\end{array}$ & $\begin{array}{l}91 \mathrm{~d} \sigma_{t} \\
(\mathrm{MPa})\end{array}$ \\
\hline $560 \mathrm{~mm}$ & 2562 & 141.1 & 153.4 & 16.3 & 18.1 \\
\hline
\end{tabular}

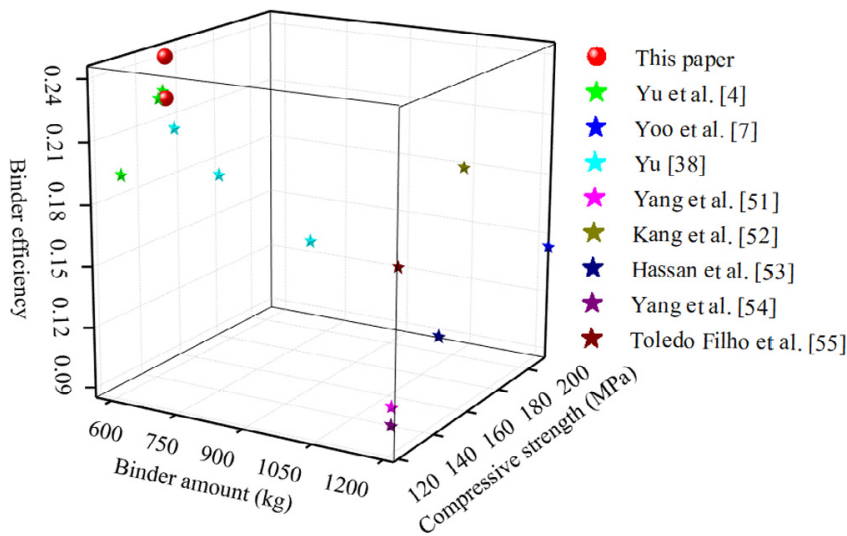

Fig. 4. Binder efficiency of the designed UHPFRC.

\subsection{Impact response}

\subsubsection{Crack propagation}

Fig. 5 shows the crack propagation on the top surface. After the first
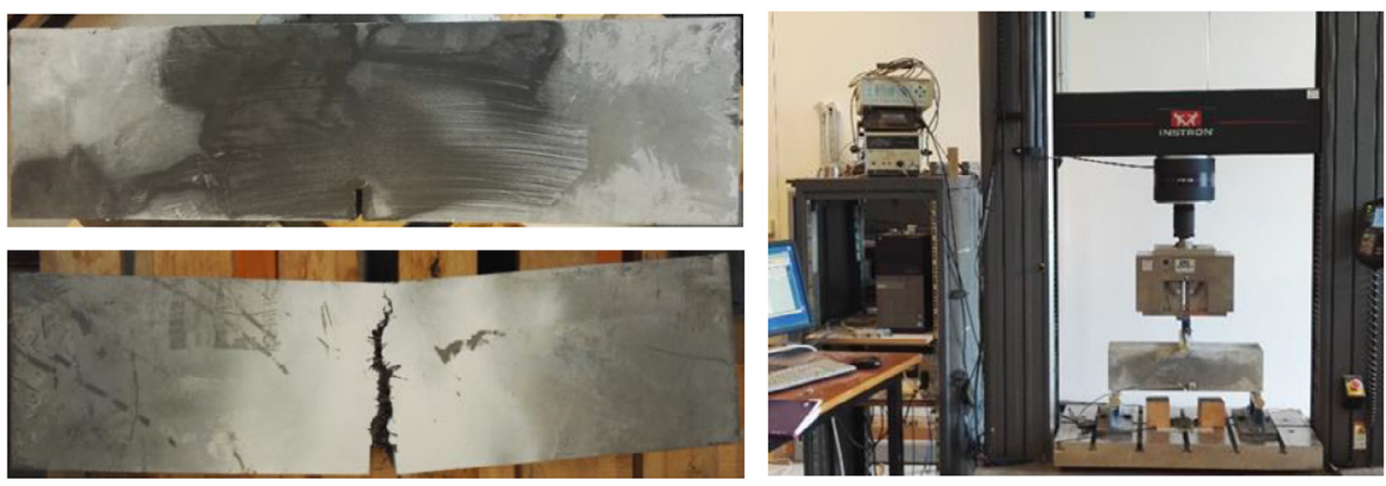

Fig. 3. Specimens and set-up of central point bending test. 

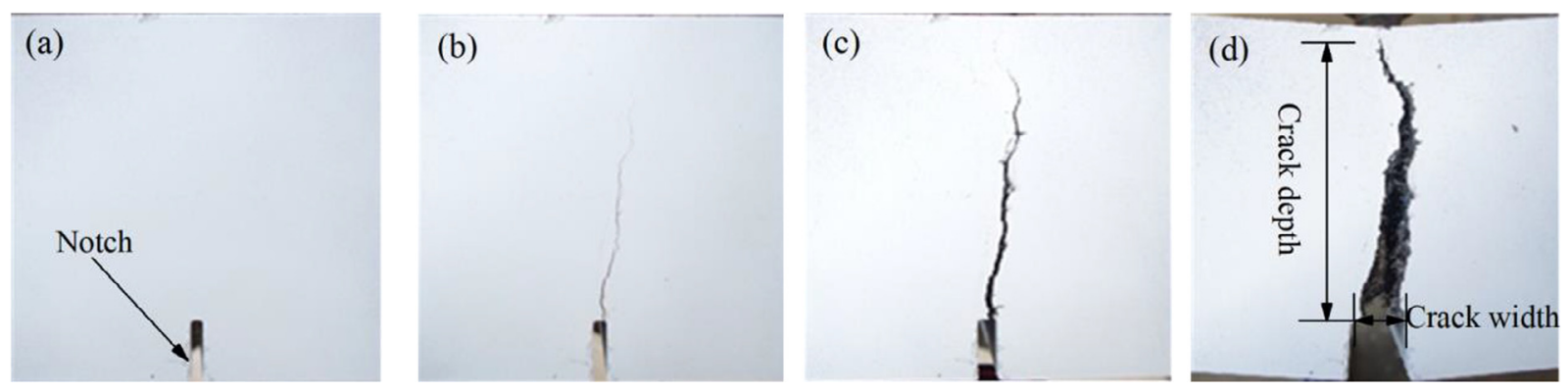

Fig. 5. Crack propagation after impact number of 0 (a), 1 (b), 2 (c) and 3 (d).

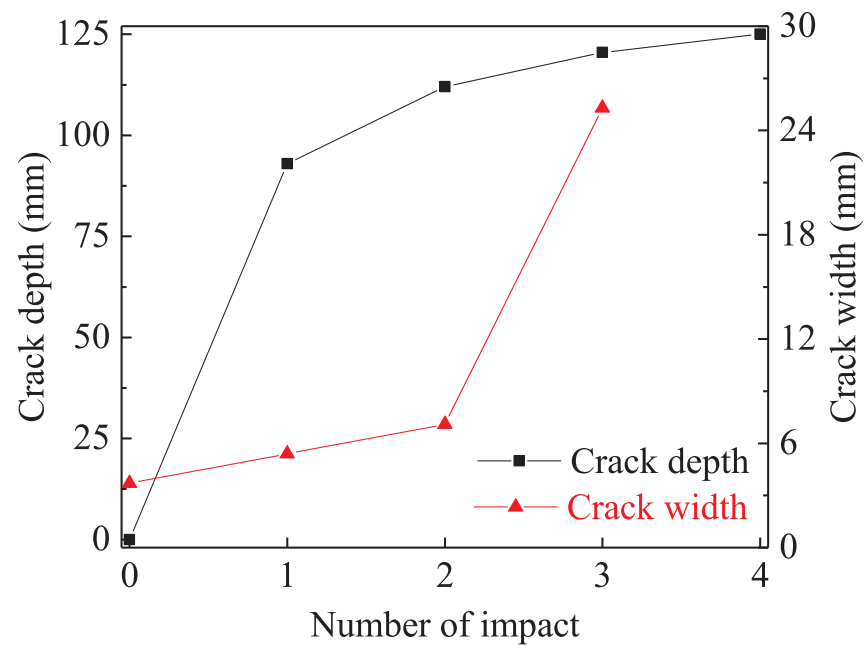

Fig. 6. Crack values vs. number of impact.

impact, a long and thin crack can be observed, and it develops further after the second impact. An obvious macro crack can be seen after the third impact. It should be pointed out that the UHPFRC beams are complete failed (broke into two parts) after repeated impact of 4 times.

The comparative analysis on the values of crack length and width is shown in Fig. 6. The crack depth and width of UHPFRC beam are not propagated simultaneously, which can be classified into three stages. At the first stage, the crack resistance is mainly depending on the brittle matrix of UHPFRC. Crack depth is developed more quickly at the initial impact, while the crack width only increases slightly. At the second stage, fibre bridge effect begins to work and the crack resistance is highly dependent on the bonding force between fibre and matrix. Both crack length and depth have a further increase and macro crack occurs with the further impact. At the third stage, the crack propagates rapidly till the complete damage, due to the pull-out of steel fibre and simultaneously drastic degeneration of crack resistance. The value saltation of crack width during the third impact can be regarded as a threshold point and a good indicator to the coming complete damage.

\subsubsection{Damage pattern}

The fracture pattern of completely damaged beam was evaluated, as shown in Fig. 7, to further understand the fracture mechanism of UHPFRC under low-velocity impact loading. The UHPFRC beams show a flexural-like fracture, only one dominant macro crack occurs along the notch. There is almost no front face-crater and rear face-scabbing, punching fracture or delamination, which can be probably observed in other composite materials under impact, based on the different impact velocity and energy, size of specimen and impactor. The fracture pattern of UHPFRC beam indicates that the crack always initiates and propagates along the notch, eventually decreasing variations of testing results, which is in line with Ref. [50]. Therefore, notched beam is proposed and suggested for impact test, attributed to certain fracture

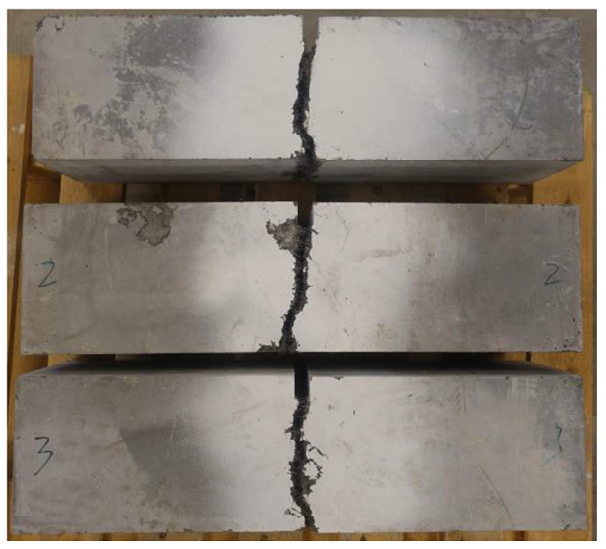

Fig. 7. Fracture pattern of completed damaged beams.

path along the notch plane. It can be concluded that the fracture of UHPFRC beam only generates in a limited local area, nearby the position of maximum moment under impact loading.

To explain the effect of steel fibre on impact resistance of UHPFRC, a qualitative comparison of steel fibres surface under static flexural and impact loading is performed, shown in Fig. 8. It should be noted that fibres are pulled out from the matrix. Although the fibre-matrix bonding surface of this thin steel fibre is large enough, no cut-off is identified because of high instinct strength of the steel fibre (see Table 3), which proves that this type of high-strength thin fibre is suitable to design impact resistant UHPFRC. In addition, longitudinal scratches can be observed on the steel fibre surfaces, attributed to the abrasion caused by the particles during the pull-out process.

The scratches subjected to impact loading are more extensive and severer than those under static loading, which can be attributed to the loading rate effect. Because the matrix is normally sensitive and enhanced under high loading rate, leading to the increase of the friction between the fibre surface and UHPFRC matrix [59]. It means that the steel fibre works more efficient and indispensable for UHPFRC subjected to impact loading.

A similar qualitative comparative analysis on coarse basalt aggregate fracture under static flexural and impact loading is presented in Fig. 9. A great difference between the fracture patterns of coarse basalt aggregate under different loadings is clearly seen. Under static flexural loading, more unbroken coarse basalt aggregates (bright) can be observed, while more broken ones (dark, splitting into two parts) exist after impact loading. It is hypothesized that cracks initiate at the relatively weaker interfacial transition zone (ITZ) between coarse aggregate and UHPFRC matrix under static loading $[59,60]$. It does not have sufficient time to seek the weak ITZ under impact loading, and directly develops through the aggregates as the shortest fracture path, which is in line with Ref. [59]. This forced fracture pattern under a higher loading rate contributes to enhanced fracture energy absorption and corresponding higher impact resistance of UHPFRC in presence of relatively stiffer and stronger coarse basalt aggregate. 


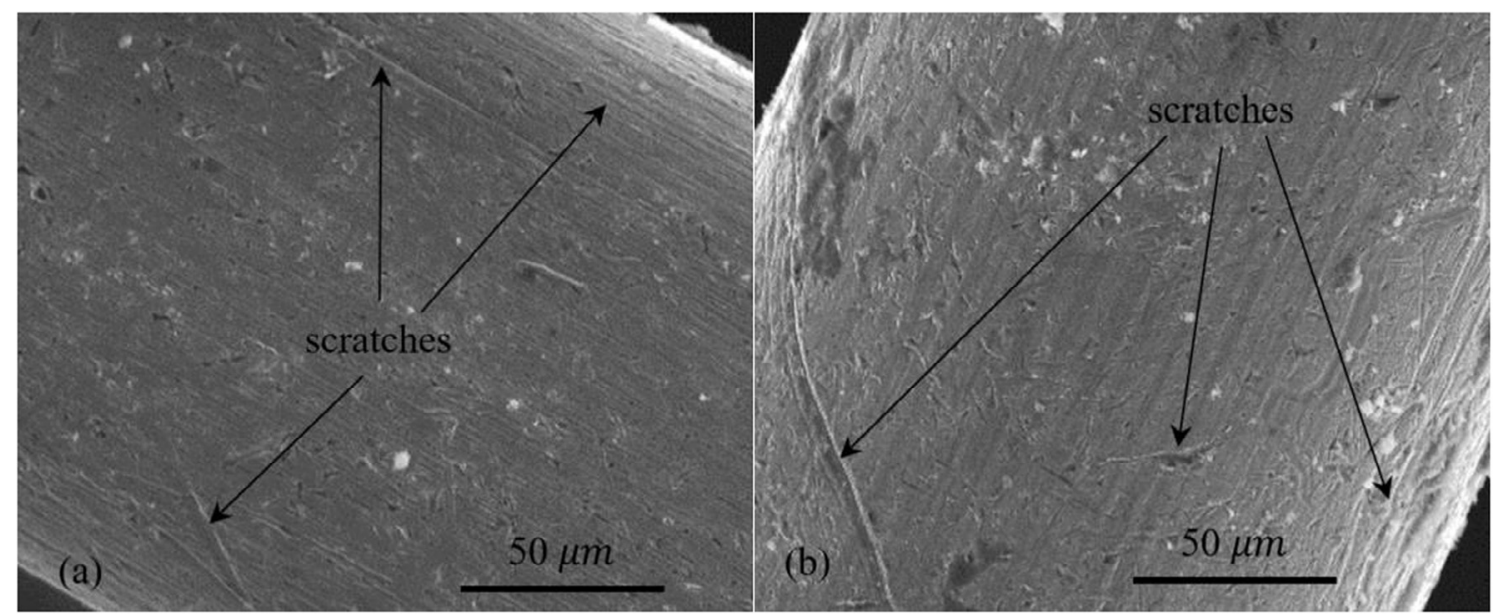

Fig. 8. Fibre surface at static (a) and impact (b) loading.

\subsubsection{Energy dissipation}

The impact resistance of UHPFRC under pendulum impact can be defined as energy dissipation or energy absorption capacity. Fig. 10 shows the absorbed energy of UHPFRC beam during each impact, calculated by Eq. (2). Before the first three impacts, the UHPFRC beam can absorb approximately $160 \mathrm{~J}$, which is about $46 \%$ of the total impact energy of hammer ( $346 \mathrm{~J}$ ). After the first impact, the UHPFRC beam still has relatively high stiffness, which will be illustrated in the flowing analysis. The impact is more like an elastic collision, which leads more gravitational potential energy of hammer to transfer into kinetic energy of UHPFRC beam. During the second impact, the stiffness of the partially damaged beam degenerates, more energy is dissipated by the deformation energy and fracture energy of concrete itself, leading to a slight increase of absorbed energy. With the further increase of damage degree, more and more fibres are pulled out and cracks of the matrix develop deeper and wider. The potential deformation energy and fracture energy decrease, which result in the decrease of energy dissipation of the UHPFRC beam.

\subsection{Post-impact properties}

\subsubsection{Residual load-deflection relationship}

Residual properties are crucial parameters for damaged composite materials to evaluate the damage degree and structural health status. The load-deflection curves in Fig. 11 highlight the differences in behaviour between the original (reference) beam and those partially damaged beams.

The curve of the reference beam can be divided into two phases of behaviour: the first phase is elastic region, where linear behaviour is

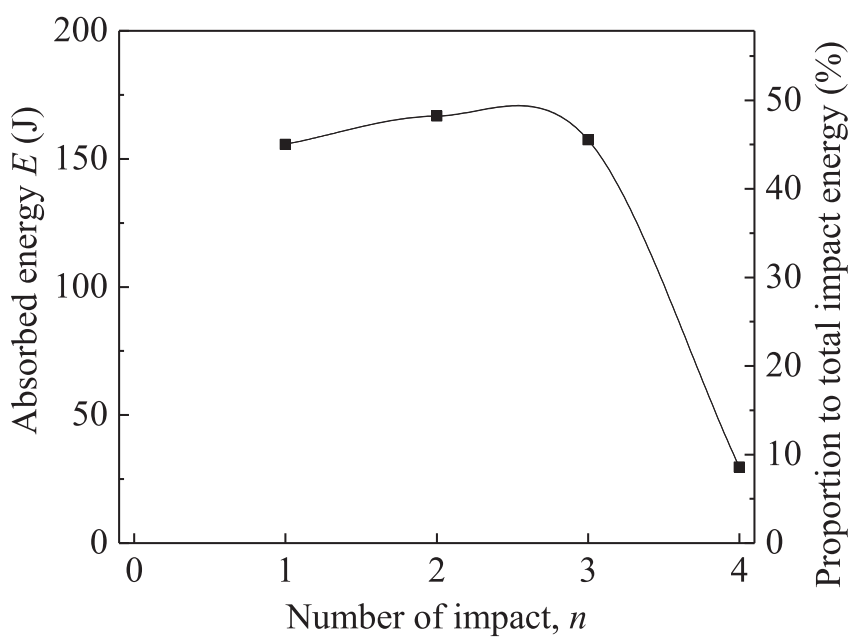

Fig. 10. Absorbed energy during each impact.

shown and no constituent materials are damaged; the second phase is strain softening region, namely post-peak period. There is a very wide strain softening region after crack initiation and propagation, due to the pull-out process of steel fibre without identification of any cut-off. The behaviour of partially damaged beam can be divided into three phases. An extra short phase corresponds to strain hardening region, which can be observed between elastic and strain softening regions, from the end of the linear elastic region to the peak flexural load. This extra strain hardening region indicates that the damaged beam undergoes some certain elastic-plastic deformation during the fibre pull-out process
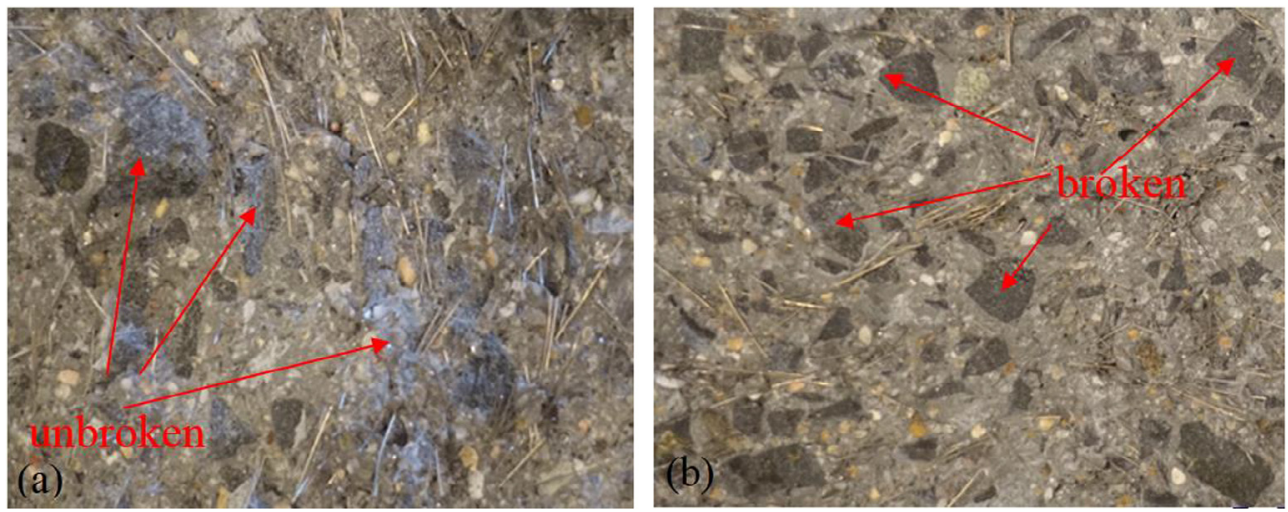

Fig. 9. Aggregate under static (a) and impact (b) loading. 


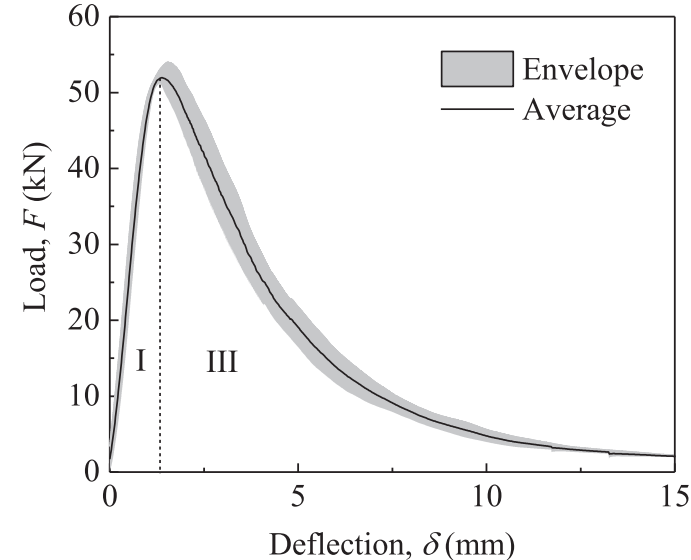

(a) impact number $=0$

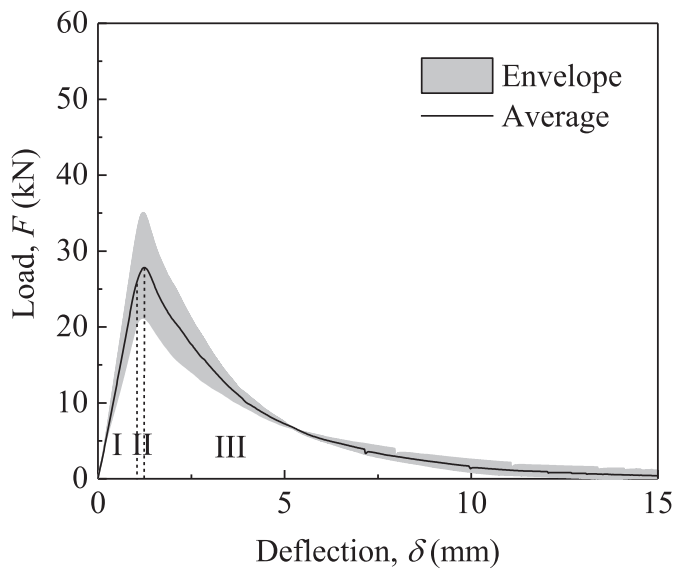

(c) impact number $=2$

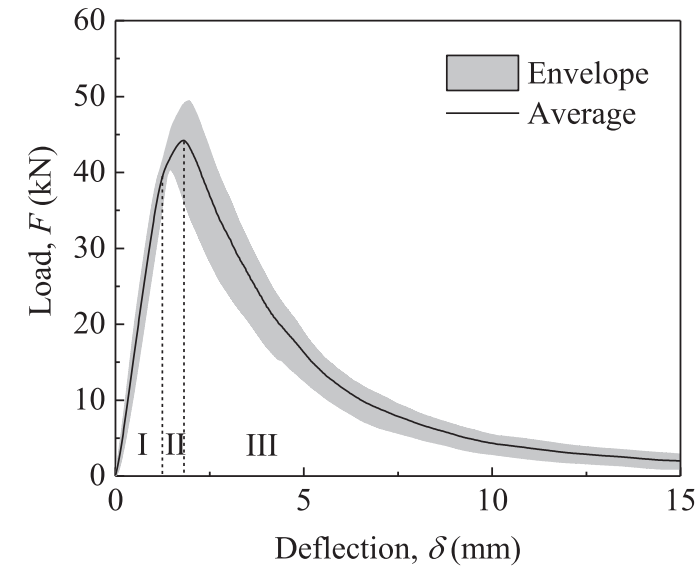

(b) impact number $=1$

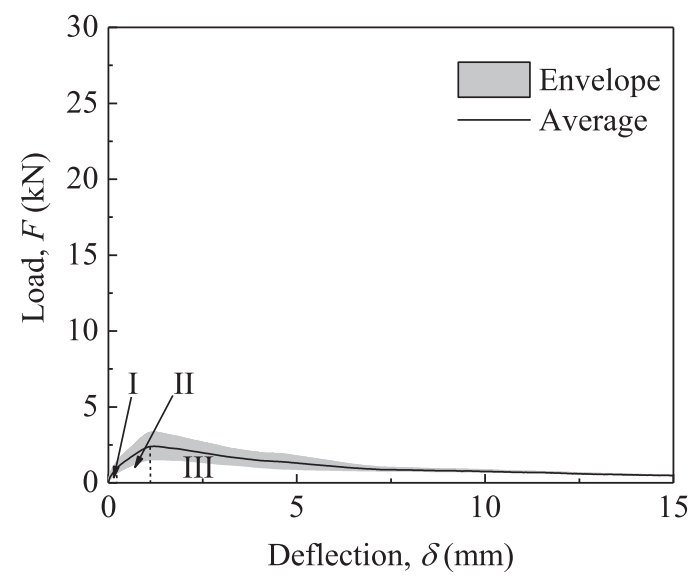

(d) impact number $=3$

Fig. 11. Load-deflection relationship after certain impact number (I: elastic region, II: strain hardening region, III: strain softening region).

under bending load. The residual load-deflection curves of beams under the first and second impact still show a very good remaining bearing capacity.

The envelopes (area covered by multiple curves) of the curves show the variation in results of repeated tests, which is likely due to local variations in fibre density and orientation $[7,61]$. It also should be noted that the strain hardening behaviour of the designed UHPFRC is not obvious, and a long load-deflection plateau does not occur. It is probably attributed to the utilized type and amount of steel fibre in this study [62]. In the future study, an appropriate length and dosage of steel fibre need to be further researched to enhance the ductility and impact resistance.

Based on the analysis on the load-deflection curves, it can be concluded that the designed UHPFRC beam has an excellent ductility and residual bearing capacity, which indicates that it is suitable to be used as impact resistant composite material.

\subsubsection{Residual strength, rigidity, toughness, impact resistance}

To further analyse and understand the post-impact properties, a number of key parameters are deduced based on the load-deflection curves, including residuals ultimate strength (ultimate flexural bearing capacity), rigidity, toughness and impact resistance.

The ultimate strength or ultimate bearing capacity $\left(F_{u}\right)$ is the peak load on the load-deflection curve, which is a basic and crucial parameter of UHPFRC. The residual ultimate bearing capacity is presented in Fig. 12(a). An empirical relation is proposed by regression analysis, following ' $-e^{x}$, law with the number of impact. The strength of UHPFRC beam decreases slightly after the 2nd impact, which means the UHPFRC can still remain a large percentage of its bearing capacity at the initial several impact.

The flexural rigidity $(E I)$ is defined as the force couple to bend a non-rigid structure or component in one unit of curvature, which can be deduced from the moment-curvature relation,

$\frac{1}{\rho}=\frac{M(x)}{E I}$

where $\rho$ is the radius of curvature, $M(x)$ is the bending moment at the position of $x$ along the length, $E$ is the Young's modulus, and $I$ is the second moment of area. The parameters in this paper are all used in SI units. Considering the Bernoulli hypothesis (plane cross-section assumption), the small deformation theory and the boundary condition in this study $[63,64]$, the flexural rigidity can be determined by interpretation of the test results from calculation of the concentrated load and corresponding deflection,

$E I=\frac{F L^{3}}{48 \delta}$

where $F$ is the concentrated load at the elastic region from central point bending test, $L$ is the length of the beam, $\delta$ is the bending flexural deflection. A linear relation is obtained with the number of impact, as shown in Fig. 12(b). Unlike the residual strength, the residual flexural rigidity tends to linearly decrease.

The flexural toughness $\left(T_{f}\right)$, representing energy absorption capacity, can be determined from the area under the load-deflection curve form flexural test,

$T_{f}=\int_{0}^{\delta_{u}} F(\delta) d \delta$ 

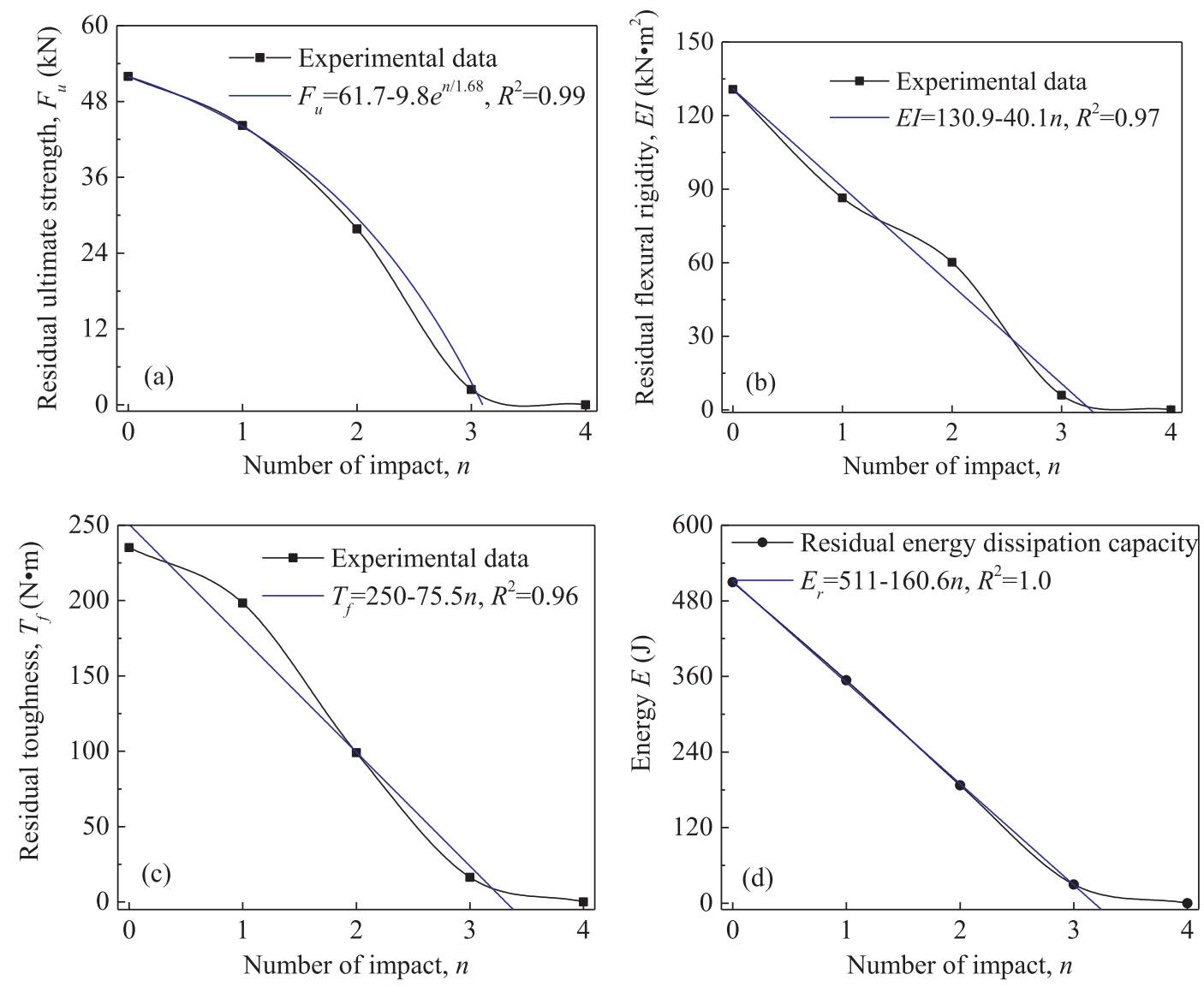

Fig. 12. Residual strength (a), rigidity (b), toughness (c) and impact resistance (d).

where $\delta_{u}$ is the maximum deflection, $\delta_{u}=15 \mathrm{~mm}$ in this study. The residual flexural toughness can be expressed by a regressed linear relation, as illustrated in Fig. 12(c). It is obvious that the residual toughness shares a similar decrease tendency to residual flexural rigidity, which indicates the residual toughness is more relevant to the rigidity rather than strength under low-velocity impact loading.

The residual impact resistance $\left(E_{r}\right)$ can be represented by remaining energy dissipation capacity, which is calculated as follows,

$E_{r}=\sum_{n}^{n_{u}} E(n)$

where $E(n)$ is the absorbed energy during the impact number of $n$, based on Eq. (2); $n_{u}$ is the total impact number till to complete damage. The regressed relation shows an ideal linear decrease, as shown in Fig. 12(d). The similar linear decrease indicates that it is possible to associate residual impact resistance with residual flexural rigidity and residual toughness.

\subsection{Damage index and levels}

It is of great significance to evaluate the damage degree and health status of protective concrete structures or components after impact events. For instance, residual ultimate bearing load and impact resistance can provide insights on assessment of the service ability subjected to both static and impact loading. Hence, it is important to propose a damage index to describe the damage degrees and levels of UHPFRC under repeated low-velocity impact loading.

In order to analyse the damage degree development, regression analysis is used to develop empirical relations, based on the collected experimental database. Empirical models are proposed to predict the post-impact properties with the number of impact $(n)$ except for the last impact, including residual strength, flexural rigidity, flexural toughness, and impact resistance,

$F_{u}(n)=61.7-9.8 e^{n / 1.68}$

$E I(n)=130.9-40.1 n$

$T_{f}(n)=250-75.5 n$

$E_{r}(n)=511-160.6 n$

A function of damage index is suggested to describe the damage degree in this study $[65,66]$,

$D(n)=1-\frac{A(n)}{A(0)}$

where $A(n)$ represents a certain property of UHPFRC, such as ultimate bending load, flexural rigidity, flexural toughness or impact resistance. $A(0)$ is the initial property without impact. According to Eqs. (8)-(12), the damage indexes of different post-impact properties can be written as,

$\left.D(n)\right|_{F_{u}}=0.189\left(e^{n / 1.68}-1\right)$

$\left.D(n)\right|_{E I}=0.306 n$

$\left.D(n)\right|_{T_{f}}=0.302 n$

$\left.D(n)\right|_{E_{r}}=0.314 n$

Based on the damage indexes, the impact damage degree can be classified mainly into three levels [67]. The first level is light damage with a damage index of $0-0.5$, corresponding to the first impact in this study. Only micro crack occurs in the UHPFRC beam at this stage. The UHPFRC beam can still be usable, due to the large residual bearing capacity and impact resistance. The second level is medium damage with a damage index of $0.5-0.75$, corresponding to the second impact 


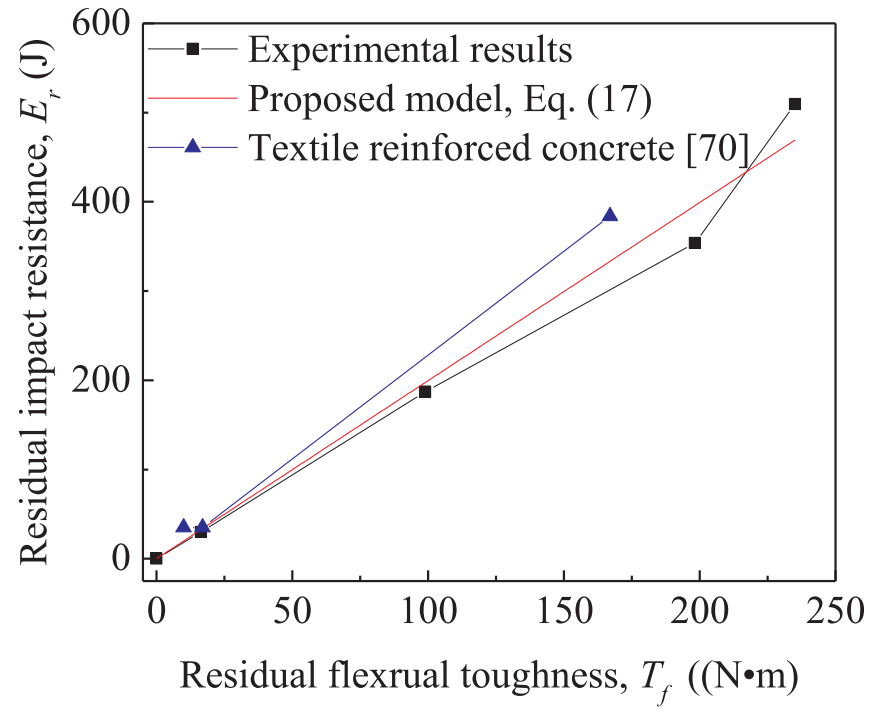

Fig. 13. Correlation between residual impact resistance and flexural toughness.

in this study. The crack propagates longer and wider to macro crack, and steel fibres slip from the matrix. The UHPFRC beam cannot be reused or maybe still reusable in some unimportant component, attributed to the degeneration of mechanical behaviour. The third level is severe damage with damage index of $0.75-1$, corresponding to the third and last impact in this study. The crack grows rapidly till the complete damage and steel fibres are pulled out. The UHPFRC beam cannot nonreusable because of almost entire loss of mechanical properties.

\subsection{Analytical modelling}

It is widely accepted that it is much more difficult to determine dynamic properties (e.g. impact resistance or energy absorption capacity) of UHPFRC than its static properties, due to the complexity of the required test. Some researchers revealed that strength is associated with impact resistance (e.g. projectile penetration), while toughness is related to tension crack and scabbing [68]. The toughness reflecting the energy absorption capacity should have a relation with impact resistance. Another research tries to predict the initial impact behaviour (delamination damage) by economical static tests (e.g. shear stress) [69]. For these reasons, a reliable analytical model is proposed to predict impact resistance with several key static properties. The residual impact resistance in Eq. (16) shares a similar damage index equation with residual rigidity and toughness by comparing with Eqs. (13)-(15), as the degeneration rates are almost the same. Hence, the flexural rigidity and toughness are more appropriate as indicators than ultimate bearing capacity, which can be used to predict the residual impact resistance of UHPFRC beam. Considering the fact that both impact resistance and flexural toughness reflect the energy absorption capacity, it is more reasonable to predict the impact resistance by flexural toughness. Hence, an empirical model is proposed to predict the residual impact resistance, based on the acquired experimental database in this study,

$E_{r}(n)=k T_{f}(n)$

where $k$ is a correlation coefficient. The correlation coefficient should show loading rate effect, which is mainly determined by the hammer (e.g. mass, velocity, texture) and specimen (e.g. shape, size, texture). In this study, the correlation coefficient is $1.996\left(R^{2}=0.99\right)$. The proposed predicting model fits very well to the experimental results, as shown in Fig. 13. The proposed model is further validated by the relation between low-velocity impact resistance and flexural toughness of textile reinforced concrete [70], as shown in Fig. 13. Nevertheless, the toughness varies at different impact conditions or loading rates [71], which probably affects the energy absorption and consequently the value of $k$. Hence, validation of the correlation coefficient $k$ for a wider application needs further investigation with a larger experimental database and different impact loading rates.

\section{Conclusions}

The present research aims to understand the response and postimpact properties of ultra-high performance fibre reinforced concrete under low-velocity impact. A reliable low-velocity impact method employing pendulum impact test set-up is designed and applied in this study. Furthermore, an analytical model is proposed to describe the impact resistance of UHPFRC by its static properties and validated against the experimental data. Based on the obtained results, the following conclusions can be drawn:

- Coarse basalt aggregate can be successfully introduced into UHPFRC by applying an optimal particle packing model with a relatively low powder content and high binder efficiency. A reliable impact testing method for UHPFRC is proposed and designed with pendulum hammer and notched specimens.

- The crack depth and width of UHPFRC beam are not propagated simultaneously, crack depth is developed more quickly at the initial several impacts. The threshold point of crack width indicates the loss of major bearing capacity and impact resistance of UHPFRC beam.

- Damage of fibre and coarse aggregate under impact loading is severer than that under static loading. Most aggregates are broken at the fracture cross-section, which directly demonstrates that they work and improve the impact resistance under impact loading.

- Under the impact loading, the residual strength of UHPFRC beams follows ' $-e^{x}$ ' law with the number of impact, while the residual rigidity, toughness and impact resistance follow linear law. The residual impact resistance has a similar damage index to the residual flexural rigidity and toughness instead of residual strength, and an analytical model to predict the residual impact resistance of UHPFRC beams with the flexural toughness is proposed and validated.

\section{Acknowledgements}

This research was carried out under the fund of China Scholarship Council and Eindhoven University of Technology. Thanks are given to Mr. Verhagen for his help to design the pendulum impact instrument and to Mr. Gang Liu for his support with impact experiments. Furthermore, the authors wish to express their gratitude to the following sponsors of the Building Materials research group at TU Eindhoven: Rijkswaterstaat Grote Projecten en Onderhoud; GranietImport Benelux; Kijlstra Betonmortel; Struyk Verwo; Attero; Enci; Rijkswaterstaat Zee en Delta-District Noord; Van Gansewinkel Minerals; BTE; V.d. Bosch Beton; Selor; GMB; Icopal; BN International; Eltomation, Knauf Gips; Hess AAC Systems; Kronos; Joma; CRH Europe Sustainable Concrete Centre; Cement \& Beton Centrum; Heros; Inashco; Keim; Sirius International; Boskalis; NNERGY; Millvision; Sappi and Studio Roex (in chronological order of joining).

\section{References}

[1] Richard P, Cheyrezy M. Composition of reactive powder concretes. Cem Concr Res 1995;25:1501-11.

[2] Kang S-T, Lee Y, Park Y-D, Kim J-K. Tensile fracture properties of an Ultra High Performance Fiber Reinforced Concrete (UHPFRC) with steel fiber. Compos Struct 2010;92:61-71.

[3] Yoo DY, Banthia N. Mechanical properties of ultra-high-performance fiber-reinforced concrete: a review. Cem Concr Compos 2016;73:267-80.

[4] Yu R, van Beers L, Spiesz P, Brouwers HJH. Impact resistance of a sustainable Ultra- 
High Performance Fibre Reinforced Concrete (UHPFRC) under pendulum impact loadings. Constr Build Mater 2016;107:203-15.

[5] Makita T, Brühwiler E. Tensile fatigue behaviour of Ultra-High Performance Fibre Reinforced Concrete combined with steel rebars (R-UHPFRC). Int J Fatigue 2014;59:145-52.

[6] Wang W, Liu J, Agostini F, Davy CA, Skoczylas F, Corvez D. Durability of an Ultra High Performance Fiber Reinforced Concrete (UHPFRC) under progressive aging. Cem Concr Res 2014;55:1-13.

[7] Yoo DY, Banthia N, Kang ST, Yoon YS. Effect of fiber orientation on the rate-dependent flexural behavior of ultra-high-performance fiber-reinforced concrete. Compos Struct 2016;157:62-70.

[8] Shin H-O, Min K-H, Mitchell D. Confinement of ultra-high-performance fiber reinforced concrete columns. Compos Struct 2017;176:124-42.

[9] Ma J, Orgass M, Dehn F, Schmidt D, Tue NV. Comparative Investigations on UltraHigh Performance Concrete with or without coarse aggregates. Proc Int Symp Ultra High Perform Concr Kassel 2004:205-12.

[10] Jiang C, Wu YF, Jiang JF. Effect of aggregate size on stress-strain behavior of concrete confined by fiber composites. Compos Struct 2017;168:851-62.

[11] Collepardi S, Coppola L, Troli R, Collepardi M. Mechanical properties of modified reactive powder concrete. ACI Spec Publ 1997;173:1-22.

[12] Wille K, Naman AE, Parra-Montesinos GJ. Ultra-high performance concrete with compressive strength exceeding $150 \mathrm{MPa}(22 \mathrm{ksi})$ : a simpler way. ACI Mater J 2011;108:46-53.

[13] Li PP, Yu QL, Brouwers HJH. Effect of coarse basalt aggregates on the properties of Ultra-high Performance Concrete (UHPC). Constr Build Mater 2018;170:649-59.

[14] Rozalija K, Darwin D. Effects of aggregate type, size, and content on concrete strength and fracture energy. Lawrence, Kansas: 1997.

[15] Máca P, Sovják R, Konvalinka P. Mix design of UHPFRC and its response to projectile impact. Int J Impact Eng 2014;63:158-63.

[16] Kim H, Kim G, Nam J, Kim J, Han S, Lee S. Static mechanical properties and impact resistance of amorphous metallic fiber-reinforced concrete. Compos Struct 2015; 134:831-44.

[17] Nicolaides D, Kanellopoulos A, Savva P, Petrou M. Experimental field investigation of impact and blast load resistance of Ultra High Performance Fibre Reinforced Cementitious Composites (UHPFRCCs). Constr Build Mater 2015;95:566-74.

[18] Kaewunruen S, Remennikov AM. Dynamic flexural influence on a railway concrete sleeper in track system due to a single wheel impact. Eng Fail Anal 2009;16:705-12.

[19] Bambach MR, Jama H, Zhao XL, Grzebieta RH. Hollow and concrete filled steel hollow sections under transverse impact loads. Eng Struct 2008;30:2859-70.

[20] ACI Committee 544. Measurement of properties of fiber reinforced concrete. ACI 5442R-89 1999;89:1-12.

[21] Badr A, Ashour AF, Platten AK. Statistical variations in impact resistance of polypropylene fibre-reinforced concrete. Int J Impact Eng 2006;32:1907-20.

[22] Alavi Nia A, Hedayatian M, Nili M, Sabet VA. An experimental and numerical study on how steel and polypropylene fibers affect the impact resistance in fiber-reinforced concrete. Int J Impact Eng 2012;46:62-73.

[23] Myers JJ, Tinsley M. Impact resistance of blast mitigation material using modified ACI drop-weight impact test. ACI Mater J 2014:339-48.

[24] Xu B, Toutanji HA, Gilbert J. Impact resistance of poly(vinyl alcohol) fiber reinforced high-performance organic aggregate cementitious material. Cem Concr Res 2010;40:347-51.

[25] Yoo D-Y, Banthia N, Kim S-W, Yoon Y-S. Response of ultra-high-performance fiberreinforced concrete beams with continuous steel reinforcement subjected to lowvelocity impact loading. Compos Struct 2015;126:233-45.

[26] Akatay A, Bora MÖ, Çoban O, Fidan S, Tuna V. The influence of low velocity repeated impacts on residual compressive properties of honeycomb sandwich structures. Compos Struct 2015;125:425-33.

[27] Caous D, Bois C, Wahl JC, Palin-Luc T, Valette J. A method to determine composite material residual tensile strength in the fibre direction as a function of the matrix damage state after fatigue loading. Composites Part B 2017;127:15-25.

[28] Lopresto V, Papa I, Langella A. Residual strength evaluation after impact tests in extreme temperature conditions. New equipment for CAI tests. Composites Part B 2017;127:44-52.

[29] Schubel PM, Luo J-J, Daniel IM. Impact and post impact behavior of composite sandwich panels. Composites Part A 2007;38:1051-7.

[30] Li PP, Yu QL, Brouwers HJH. Effect of PCE-type superplasticizer on early-age behaviour of ultra-high performance concrete (UHPC). Constr Build Mater 2017;153:740-50.

[31] Soufeiani L, Raman SN, Bin Jumaat MZ, Alengaram UJ, Ghadyani G, Mendis P. Influences of the volume fraction and shape of steel fibers on fiber-reinforced concrete subjected to dynamic loading - a review. Eng Struct 2016;124:405-17.

[32] Brouwers HJH, Radix HJ. Self-compacting concrete: theoretical and experimental study. Cem Concr Res 2005;35:2116-36.

[33] Brouwers HJH. Particle-size distribution and packing fraction of geometric random packings. Phys Rev E 2006;74:031309.

[34] Quercia G, Hüsken G, Brouwers HJH. Water demand of amorphous nano silica and its impact on the workability of cement paste. Cem Concr Res 2012;42:344-57.

[35] Yu QL, Spiesz P, Brouwers HJH. Development of cement-based lightweight composites - Part 1: mix design methodology and hardened properties. Cem Concr Compos 2013;44:17-29.

[36] Wang X, Wang K, Taylor P, Morcous G. Assessing particle packing based self-consolidating concrete mix design method. Constr Build Mater 2014;70:439-52.

[37] Hunger M. An integral design concept for ecological self-compacting concrete PhD thesis Eindhoven, the Netherland: Eindhoven University of Technology; 2010

[38] Yu R. Development of sustainable protective Ultra-High Performance Fibre Reinforced Concrete (UHPFRC) PhD thesis Eindhoven, the Netherland: Eindhoven
University of Technology; 2015

[39] EN12350-8. Testing fresh concrete - Part 8: self-compacting concrete - slump-flow test. Br Stand. Institution-BSI CEN Eur. Comm. Stand.; 2007.

[40] EN 12390-3. Testing hardened concrete - Part 3: compressive strength of test specimens. Br Stand. Institution-BSI CEN Eur. Comm. Stand.; 2009.

[41] EN 12390-6. Testing hardened concrete - Part 6: tensile splitting strength of test specimens. Br Stand. Institution-BSI CEN Eur. Comm. Stand.; 2000.

[42] Zhou X, Ghaffar SH, Dong W, Oladiran O, Fan M. Fracture and impact properties of short discrete jute fibre-reinforced cementitious composites. Mater Des 2013;49:35-47.

[43] Yoo D-Y, Yoon Y-S, Banthia N. Flexural response of steel-fiber-reinforced concrete beams: effects of strength, fiber content, and strain-rate. Cem Concr Compos 2015;64:84-92.

[44] Wu M, Chen Z, Zhang C. Determining the impact behavior of concrete beams through experimental testing and meso-scale simulation: I. Drop-weight tests. Eng Fract Mech 2015;135:94-112.

[45] RILEM TC 162-TDF. Test and design methods for steel fibre reinforced concrete: bending test. Mater Struct 2002;35:579-82.

[46] EN 14651. Test method for metallic fibred concrete - Measuring the flexural tensile strength (limit of proportionality (LOP), residual). Br Stand. Institution-BSI CEN Eur. Comm. Stand.; 2005.

[47] Zhang XX, Abd Elazim AM, Ruiz G, Yu RC. Fracture behaviour of steel fibre-reinforced concrete at a wide range of loading rates. Int J Impact Eng 2014;71:89-96.

[48] Badr A, Ashour AF. Modified ACI drop-weight impact test for concrete. ACI Mater J 2005:249-55.

[49] Zhu X-C, Zhu H, Li H-R. Drop-weight impact test on U-shape concrete specimens with statistical and regression analyses. Materials (Basel) 2015;8:5877-90.

[50] Sivakumar A, Sounthararajan VM. Toughness characterization of steel fibre reinforced concrete. A review on various international standards. J Civ Eng Constr Technol 2013;4:65-9.

[51] EFNARC. The European guidelines for self-compacting concrete. Eur Guidel Self Compact Concr 2005;63.

[52] Bentz DP, Ferraris CF, Jones SZ, Lootens D, Zunino F. Limestone and silica powder replacements for cement: early-age performance. Cem Concr Compos 2017;78:43-56.

[53] Yu QL, Brouwers HJH. Development of a self-compacting gypsum-based lightweight composite. Cem Concr Compos 2012;34:1033-43.

[54] Yang SL, Millard SG, Soutsos MN, Barnett SJ, Le TT. Influence of aggregate and curing regime on the mechanical properties of ultra-high performance fibre reinforced concrete (UHPFRC). Constr Build Mater 2009;23:2291-8.

[55] Kang ST, Lee BY, Kim J-K, Kim YY. The effect of fibre distribution characteristics on the flexural strength of steel fibre-reinforced ultra high strength concrete. Constr Build Mater 2011;25:2450-7.

[56] Hassan AMT, Jones SW, Mahmud GH. Experimental test methods to determine the uniaxial tensile and compressive behaviour of ultra high performance fibre reinforced concrete (UHPFRC). Constr Build Mater 2012;37:874-82.

[57] Yang IH, Joh C, Kim B-S. Structural behavior of ultra high performance concrete beams subjected to bending. Eng Struct 2010;32:3478-87.

[58] Toledo Filho RD, Koenders EAB, Formagini S, Fairbairn EMR. Performance assessment of ultra high performance fiber reinforced cementitious composites in view of sustainability. Mater Des 2012;36:880-8.

[59] Tai YS, El-Tawil S, Chung TH. Performance of deformed steel fibers embedded in ultra-high performance concrete subjected to various pullout rates. Cem Concr Res 2016;89:1-13.

[60] Erdem S, Blankson MA. Fractal-fracture analysis and characterization of impactfractured surfaces in different types of concrete using digital image analysis and 3D nanomap laser profilometery. Constr Build Mater 2013;40:70-6.

[61] Meng W, Khayat KH. Improving flexural performance of ultra-high-performance concrete by rheology control of suspending mortar. Composites Part B 2017;117:26-34.

[62] Gesoglu M, Güneyisi E, Muhyaddin GF, Asaad DS. Strain hardening ultra-high performance fiber reinforced cementitious composites: effect of fiber type and concentration. Composites Part B 2016;103:74-83.

[63] Truong BT, Bui TT, Limam A, Si Larbi A, Le Nguyen K, Michel M. Experimental investigations of reinforced concrete beams repaired/reinforced by TRC composites. Compos Struct 2017;168:826-39.

[64] Safdar M, Matsumoto T, Kakuma K. Flexural behavior of reinforced concrete beams repaired with ultra-high performance fiber reinforced concrete (UHPFRC). Compos Struct 2016;157:448-60.

[65] Knab LI, Clifton JR. Cumulative damage of reinforced concrete subjected to repeated impact. Cem Concr Res 1982;12:359-70.

[66] Hashin Z. Cumulative damage theory for composite materials: Residual life and residual strength methods. Compos Sci Technol 1985;23:1-19.

[67] Kaewunruen S, Remennikov AM. Progressive failure of prestressed concrete sleepers under multiple high-intensity impact loads. Eng Struct 2009;31:2460-73.

[68] Kim H, Kim G, Gucunski N, Nam J, Jeon J. Assessment of flexural toughness and impact resistance of bundle-type polyamide fiber-reinforced concrete. Composites Part B 2015;78:431-46.

[69] Sutherland LS, Guedes Soares C. The use of quasi-static testing to obtain the lowvelocity impact damage resistance of marine GRP laminates. Composites Part B 2012;43:1459-67.

[70] Tsesarsky M, Peled A, Katz A, Anteby I. Strengthening concrete elements by confinement within textile reinforced concrete (TRC) shells - static and impact properties. Constr Build Mater 2013;44:514-23.

[71] Dey V, Bonakdar A, Mobasher B. Low-velocity flexural impact response of fiberreinforced aerated concrete. Cem Concr Compos 2014;49:100-10. 